\title{
TINGKAT KEPUASAN PELAYANAN KESEHATAN DI PUSKESMAS KEBON HANDIL KOTA JAMBI TAHUN 2020
}

\section{Level of Health Service Satisfaction in Kebon Handil Health Center in Jambi City 2020}

\author{
Syafriana $^{1}$, Irawati Sukandar ${ }^{1}$, Renny Listiawaty $^{2}$ \\ ${ }^{1}$ Program Studi Kesehatan Masyarakat STIKES Harapan Ibu, Jambi, Indonesia \\ ${ }^{2}$ Pemberdayaan Masyarakat, Jambi, Indonesia
}

\begin{abstract}
Abstrak
Kepuasan pelayanan jasa kesehatan tercapai jika, apa yang didapatkan pasien melebihi harapannya. Puskesmas Kebon Handil merupakan Puskesmas Perkotaan yang telah di Akreditasi, Namun dalam pelayanannya terjadi penurunan hasil Indeks kepuasan masyarakat yang dilakukan oleh bagian organisasi setda kota Jambi tahun 2018 76,26\% menjadi 69,7\% pada tahun 2019.Jenis penelitian ini kuantitatif dengan metode deskritif, Dimensi yang digunakan adalah dimensi kehandalan (Reliability), daya tanggap (Responsiveness), jaminan (Assurance), empati (Emphaty), dan bukti fisik (Tangeble). Pengambilan sampel menggunakan metode purposive sampling, sampel berjumlah 95 pasien dari jumlah populasi kunjungan pasien bulan Agustus s/d Oktober 2019 .Penelitian ini dilaksanakan pada tanggal 23 s/d 31 bulan Januari 2020 di Puskesmas Kebon Handil Kota Jambi.Tujuan penelitian adalah untuk melihat tingkat kepuasan pasien pada pelayanan kesehatan, sehingga dapat diketahui unsur yang dipertahankan dan diperbaiki oleh puskesmas dan dapat meningkatkan kualitas pelayanan. Hasil penelitian dianalisis dengan menggunakan diagram kartesius membandingkan harapan dan kenyataan yang menggambarkan tingkat kepuasan pasien terhadapat pelayanan kesehatan. Dalam aspek kehandalan $86,28 \%$, daya tanggap $84,38 \%$, jaminan $84,63 \%$, empati $88,93 \%$, bukti fisik $78,33 \%$. Tingkat kepuasan secara keseluruhan $86,28 \%$.
\end{abstract}

Kata Kunci: Tingkat Kepuasan, Pelayanan Kesehatan, Puskesmas

\begin{abstract}
Satisfaction with health services is obtained if what the patient receives exceeds his expectations. Kebon Handil Health Center is an urban health center that has accreditation, but in its service there was a decrease in the community satisfaction index conducted by the organizational division of Jambi City in $201876.26 \%$ to $69.7 \%$ in 2019. This type of research is quantitative with descriptive methods, the dimensions used are the dimensions of reliability (reliability), responsiveness (Responsiveness), Guarantee (Guarantee), empathy (Emphaty), and physical evidence (Tangeble). Sampling using a purposive sampling method, a sample of 95 patient participation from the number of patient visits in August to October 2019. This research was conducted on 23 to 31 January 2020 at the Kebon Handil Health Center in Jambi City.The purpose of this study is to see the level of patient satisfaction in health services, so that it can be expected can not be accepted and improved by the health center and can improve the quality of service. The results of the study were analyzed using a Cartesian diagram comparing expectations and expectations assessed by the level of patient satisfaction with health care. In the aspect of credibility $86.28 \%$, responsiveness $84.38 \%$, Guarantee $84.63 \%$, empathy $88.93 \%$, physical evidence $78.33 \%$. The overall satisfaction level is $86.28 \%$.
\end{abstract}

Keywords: Satisfaction Level, Health Services, Puskesmas

Korespondensi : Syafriana

E-mail : nanadjupri43@gmail.com 


\section{PENDAHULUAN}

Pemerintah dalam beberapa waktu terakhir terus berupaya untuk meningkatkan kualitas pelayanan publik yang diselenggarakan oleh instansi pemerintah. Sebagaimana amanat yang tertuang dalam Undang-Undang Nomor 25 Tahun 2009 tentang Pelayanan Publik, negara memiliki kewajiban melayani setiap warga negara dan penduduk untuk memenuhi hak dan kebutuhan dasarnya dalam kerangka pelayanan publik(1). Di Indonesia setelah adanya otonomi daerah, perubahan sistem pemerintahan ini juga diiringi dengan tuntutan perubahan kualitas pelayanan yang diharapkan masyarakat (2). Penyediaan pelayanan publik yang berkualitas merupakan kewajiban yang harus dilakukan oleh setiap penyelenggara Negara (3). Konsepsi otonomi daerah sebagaimana diatur dalam UU No. 32 Tahun 2004 telah memberikan kewenangan dan keleluasan pemerintah daerah untuk dapat menyelenggarakan pelayanan publik yang berkualitas(4).

Puskesmas harus mulai memikirkan pentingnya program pelayanan pelanggan secara lebih matang melalui kualitas pelayanan (5). Bagaimana data apa saja yang bisa dilakukan agar kepuasan pelanggan bisa terlampaui dengan baik, karena kepuasan pelanggan tidak hanya diperoleh dari kualitas produk (6). Memperhatikan atau bahkan mengedepankan orientasi untuk rnelayani pelanggan (customer service) yang dapat memuaskan pelanggan (7). Kepuasan pasien bias merupakan cerminan dari hasil kualitas pelayananyang relatif baik tetapi belum bias memuaskan pasien. Kepuasan pasien adalah suatu tingkat perasaan pasien yang timbul sebagai akibat dari kinerja layanan kesehatan yang diperolehnya setelah pasien membandingkannya denagan apa yang diharapkanya (8).

Salah satu pengukuran kualitas Puskesmas melalui survey kepuasan masyarakat IKM (Indeks Kepuasan Masyarakat) (3). Survei ini dilakukan sebagai alat ukur untuk melihat kepuasan pelanggan terhadap layanan yang diberikan oleh puskesmas (9). Survei kepuasan kepada masyarakat juga dilakukan oleh pemerintah daerah dan Ombusman. Dari haril survei yang dilakukan oleh pemerintah daerah nilai kepuasan pelayanan di puskesmas Kebon Handil pada tahun 2018 sebesar 76,26\% (10) nilai ini masih belum mencapai nilai yang ditargetkan sebesar $85 \%$ dan terjadi penurunan pada tahun 2019 yaitu 69,7\% (11). Dari hasil survei kepuasan pelanggan yang dilakukan, Unsur pelayanan yang terendah adalah unsur waktu tunggu, standar pelayanan dan sikap petugas pelayanan. Tujuan Peneltian ini adalah untuk mengetahuinya kualitas pelayanan kesehatan di Puskesmas Kebon Handil menuju pelayanan publik yang berkualitas baik upaya kesehatan perorangan maupun upaya kesehatan masyarakat berdasarkan dari lima dimensi mutu yaitu Tangibles, Riliability, Responsiveness, Assurance, Empathy pada tahun 2020

\section{METODE}

Penelitian ini dilakukan pada pasien di Puskesmas Kebon Handil kota Jambi pada tanggal 23 s/d 31 Januari 2020. Variabel yang diteliti terdiri dari 5 dimensi mutu pelayanan antara lain (Tangibles, Riliability, Responsiveness, Assurance, Empathy) terhadap kepuasan pasien di Puskesmas kebon handil dengan jumlah sampel sebanyak 95 pasien yang berobat di puskesmas kebon handil dari jumlah populasi pasien yang berkunjung dari 
bulan Agustus sampai bulan Oktober 2019 di Puskesmas kebon handil Kota Jambi sebanyak 8.794 pasien. Penelitian ini adalah penelitian deskriptif kuantitatif dengan pendekatan cross sectional dan pengumpulan data berupa kuesioner kemudian dianalisis secara univariat yang kemudian dianalisa dengan IPA (Importance performan Analisis) menggunakan diagram kartesius.

\section{HASIL PENELITIAN.}

Tabel 1. Distribusi tingkat kesesuaian kepuasan pasien berdasarkan dimensi Reliability /Kehandalan di Puskesmas Kebon Handil Kota Jambi Tahun 2020

\begin{tabular}{|c|c|c|c|c|}
\hline No & Indikator Dimensi & $\begin{array}{l}\text { Harapan } \\
\text { (Y) }\end{array}$ & $\begin{array}{l}\text { Kenyataan } \\
\text { (X) }\end{array}$ & $\begin{array}{c}\text { Tingkat } \\
\text { Kepuasan }(\%)\end{array}$ \\
\hline 1 & $\begin{array}{l}\text { Diagnosa dokter terhadap penyakit pasien } \\
\text { akurat }\end{array}$ & 406 & 344 & 84,73 \\
\hline 2 & $\begin{array}{l}\text { Dokter memeriksa pasien dengan sungguh- } \\
\text { sungguh }\end{array}$ & 401 & 343 & 85,54 \\
\hline 3 & $\begin{array}{l}\text { Dokter memberikan resep yang tepat kepada } \\
\text { pasien }\end{array}$ & 409 & 381 & 93,15 \\
\hline 4 & Perawat membantu dokter dengan baik & 404 & 343 & 84,90 \\
\hline 5 & $\begin{array}{l}\text { Puskesmas dapat memenuhi pelayanan yang } \\
\text { dijanjikan kepada masyarakat }\end{array}$ & 409 & 346 & 84,60 \\
\hline 6 & $\begin{array}{l}\text { Puskesmas dapat memberikan pelayanan } \\
\text { yang cepat dan tidak berbelit-belit }\end{array}$ & 411 & 303 & 73,72 \\
\hline \multirow[t]{2}{*}{7} & $\begin{array}{l}\text { Puskesmas memberikan informasi pelayanan } \\
\text { kesehatan terhadap masyarakat }\end{array}$ & 410 & 353 & 86,10 \\
\hline & Total & 2850 & 2413 & 84,67 \\
\hline
\end{tabular}

Berdasarkan dari tabel 1 menunjukan bahwa Pasien yang berobat ke Puskesmas Kebon Handil Tingkat Kepuasaan berdasarkan Dimensi Kehandalan/Reliability antara kenyataan dengan harapan sebesar $86,28 \%$.
Persentase terendah yaitu puskesmas dapat memberikan pelayanan yang cepat dan tidak berbelit-belit sebesar $73,72 \%$ dan persentase tertinggi yaitu Dokter memberikan resep yang tepat kepada pasien sebesar $93,15 \%$. 
Tabel 2. Distribusi tingkat kesesuaian kepuasan Responden Berdasarkan Dimensi Responsiveness / Daya Tanggap di Puskesmas Kebon Handil Kota Jambi Tahun 2020

\begin{tabular}{clccc}
\hline No & \multicolumn{1}{c}{ Indikator Dimensi } & $\begin{array}{c}\text { Harapan } \\
(\mathrm{Y})\end{array}$ & $\begin{array}{c}\text { Kenyataan } \\
(\mathrm{X})\end{array}$ & $\begin{array}{c}\text { Tingkat } \\
\text { Kepuasan (\%) }\end{array}$ \\
\hline 1 & $\begin{array}{l}\text { Dokter bersedia mendengarkan keluhan dari } \\
\text { pasien }\end{array}$ & 409 & 347 & 84,84 \\
$2 \quad \begin{array}{l}\text { Petugas puskesmas memberikan informasi } \\
\text { yang dibutuhkan dengan baik }\end{array}$ & 405 & 345 & 85,19 \\
$3 \quad \begin{array}{l}\text { Petugas puskesmas/perawat memberi tahu } \\
\text { bilka ada keterlambatan pemeriksaan pasien }\end{array}$ & 408 & 343 & 84,07 \\
$4 \quad \begin{array}{l}\text { Putugas Apotek memberi tahu lamanya } \\
\text { proses pemberian obat } \\
\text { Total }\end{array}$ & 404 & 337 & 83,42 \\
\hline
\end{tabular}

Berdasarkan dari tabel 2 menunjukan bahwa Pasien yang berobat ke Puskesmas Kebon Handil Tingkat Kepuasaan berdasarkan Dimensi Kehandalan/Reliability antara kenyataan dengan harapan sebesar $86,28 \%$.
Persentase terendah yaitu puskesmas dapat memberikan pelayanan yang cepat dan tidak berbelit-belit sebesar $73,72 \%$ dan persentase tertinggi yaitu Dokter memberikan resep yang tepat kepada pasien sebesar $93,15 \%$.

Tabel 3. Distribusi tingkat kesesuaian kepuasan Responden Berdasarkan Dimensi Assurance/ Jaminan di Puskesmas Kebon Handil Kota Jambi Tahun 2020

\begin{tabular}{clccc}
\hline No & \multicolumn{1}{c}{ Indikator Dimensi } & $\begin{array}{c}\text { Harapan } \\
(\mathrm{Y})\end{array}$ & $\begin{array}{c}\text { Kenyataan } \\
(\mathrm{X})\end{array}$ & $\begin{array}{c}\text { Tingkat } \\
\text { Kepuasan (\%) }\end{array}$ \\
\hline 1 & $\begin{array}{l}\text { Petugas puskesmas selalu sabar menghadapi } \\
\text { keluh kesah pasien }\end{array}$ & 406 & 342 & 84,24 \\
2 & $\begin{array}{l}\text { Dokter selalu ramah terhadap setiap pasien } \\
\text { yang datang ke ruangannya }\end{array}$ & 407 & 340 & 83,54 \\
$\quad \begin{array}{l}\text { Semua petugas puskesmas selalu } \\
\text { menampilkan senyum terhadap pasien yang } \\
\text { datang }\end{array}$ & 401 & 341 & 85,04 \\
4 & $\begin{array}{l}\text { Dokter dengan sabar memberi penjelasan } \\
\text { mengenai penyakit yang diderita pasien }\end{array}$ & 405 & 344 & 84,94 \\
$\quad \begin{array}{l}\text { Dokter memberitahu alasan atau timbulnya } \\
\text { penyakit yang diderita pasien } \\
\text { Total }\end{array}$ & 405 & 346 & 85,43 \\
\hline
\end{tabular}

Berdasarkan dari tabel 3 menunjukan bahwa Pasien yang berobat ke Puskesmas Kebon Handil Tingkat kepuasan berdasarkan Dimensi Jaminan/Assurance antara kenyataan dengan harapan sebesar $84,63 \%$, Persentase terendah yaitu Dokter selalu ramah terhadap setiap pasien yang datang ke ruangannya sebesar 83,54\%, sedangkan persentase tertinggi yaitu Dokter memberitahu alasan atau timbulnya penyakit yang diderita pasien sebesar $85,43 \%$. 
Tabel 4. Distribusi tingkat kesesuaian kepuasan Responden Berdasarkan Dimensi Empati / Emphaty di Puskesmas Kebon Handil Kota Jambi Tahun 2020

\begin{tabular}{|c|c|c|c|c|}
\hline No & Indikator Dimensi & $\begin{array}{l}\text { Harapan } \\
(\mathrm{Y})\end{array}$ & $\begin{array}{l}\text { Kenyataan } \\
(\mathrm{X})\end{array}$ & $\begin{array}{c}\text { Tingkat } \\
\text { Kepuasan }(\%)\end{array}$ \\
\hline 1 & $\begin{array}{l}\text { Dokter selalu ingat terhadap } \\
\text { permasalahan/keluhan pasien sebelumnya }\end{array}$ & 384 & 333 & 86,72 \\
\hline 2 & $\begin{array}{l}\text { Dokter selalu menyanyakan kabar dan } \\
\text { keadaan pasien }\end{array}$ & 387 & 334 & 86,30 \\
\hline 3 & $\begin{array}{l}\text { Dokter selalu mendengarkan dengan } \\
\text { seksama semua keluhan pasien }\end{array}$ & 392 & 336 & 85,71 \\
\hline 4 & $\begin{array}{l}\text { Dokter dapat mengenal setiap pasien yang } \\
\text { datang berobat }\end{array}$ & 377 & 330 & 87,53 \\
\hline 5 & $\begin{array}{l}\text { Petugas pendaftaran puskesmas selalu } \\
\text { menanyakan kabar dari setiap pasien yang } \\
\text { datang }\end{array}$ & 378 & 334 & 88,36 \\
\hline 6 & $\begin{array}{l}\text { Petugas puskesmas dapat mengenal pasien } \\
\text { dengan baik }\end{array}$ & 374 & 331 & 88,50 \\
\hline 7 & $\begin{array}{l}\text { Kesediaan petugas untuk meminta maaf bila } \\
\text { terjadi kesalahan }\end{array}$ & 391 & 388 & 99,23 \\
\hline & Total & 2683 & 2386 & 88,93 \\
\hline
\end{tabular}

Berdasarkan dari tabel 4 menunjukan bahwa Pasien yang berobat ke Puskesmas Kebon Handil Tingkat kepuasan berdasarkan Dimensi Empati/Emphaty antara kenyataan dengan harapan sebesar semua keluhan pasien sebesar 85,71\%. Dan persentase tertinggi yaitu Kesediaan petugas untuk meminta maaf bila terjadi kesalahan sebesar 99,23\%.

Tabel 5. Distribusi tingkat kesesuaian kepuasan Responden Berdasarkan Dimensi Tangible / Bukti Fisik di Puskesmas Kebon Handil Kota Jambi Tahun 2020

\begin{tabular}{clccc}
\hline No & \multicolumn{1}{c}{ Indikator Dimensi } & $\begin{array}{c}\text { Harapan } \\
(\mathrm{Y})\end{array}$ & $\begin{array}{c}\text { Kenyataan } \\
(\mathrm{X})\end{array}$ & $\begin{array}{c}\text { Tingkat } \\
\text { Kepuasan (\%) }\end{array}$ \\
\hline 1 & $\begin{array}{l}\text { Puskesmas telah memiliki gedung yang } \\
\text { bersih dan terawat serta petugas yang rapi }\end{array}$ & 404 & 344 & 85,15 \\
2 & $\begin{array}{l}\text { Puskesmas telah memiliki peralatan } \\
\text { kesehatan yang memadai }\end{array}$ & 409 & 344 & 84,11 \\
$\quad \begin{array}{l}\text { Puskesmas telah memiliki ruangan tunggu } \\
\text { yang memadai untuk menunjang pasien yang } \\
\text { datang }\end{array}$ & 406 & 287 & 70,69 \\
4 & $\begin{array}{l}\text { Puskesmas telah memiliki apotek dengan } \\
\text { jumlah obat yang lengkap }\end{array}$ & 413 & 334 & 80,87 \\
$\quad \begin{array}{l}\text { Ruang pemeriksaan pasien memadai dan } \\
\text { terjaga privasinya }\end{array}$ & 403 & 285 & 70,72 \\
\hline
\end{tabular}


Berdasarkan dari tabel 5 menunjukan bahwa Pasien yang berobat ke Puskesmas Kebon Handil Tingkat kepuasan berdasarkan Dimensi Bukti Fisik/Tangible antara kenyataan dengan harapan sebesar $78,33 \%$. Persentase terendah yaitu puskesmas telah memiliki ruangan tunggu yang memadai untuk menunjang pasien yang datang sebesar $70,69 \%$ dan persentase tertinggi yaitu Puskesmas telah memiliki gedung yang bersih dan terawatt serta petugas yang rapih. Sebesar $85,15 \%$.

\section{PEMBAHASAN}

Berdasarkan dari hasil penelitian yang telah dilakukan peneliti tentang tingkat kepuasan pelayanan di Puskesmas kebon handil tahun 2020 dapat diketahui bahwa antara harapan dan kenyataan yang dirasakan sebelum mendapatkan pelayanan dan setelah mendapatkan pelayanan bagi pasien di puskesmas kebon handil tahun 2020, maka diperoleh presentase kesesuaian sebesar $85,75 \%$ dari atribut harapan dan kenyataan terhadap dimensi mutu.

\section{Dimensi Kehandalan / Reliability}

Berdasarkan hasil penelitian, pencapaian dimensi kehandalan (Reliability) di Puskesmas Kebon Handil tahun 2020 sebesar 86,28\%. Ada tujuh atribut dimensi kehandalan yaitu Diagnosa dokter terhadap penyakit pasien akurat sebesar $84,73 \%$, Dokter memeriksa pasien dengan sungguh-sungguh 85,54\%, Dokter memberika resep yang tepat kepada pasien 93,15\%, Perawat membantu dokter dengan baik 84,90, Puskesmas dapat memenuhi pelayanan yang dijanjikan kepada masyarakat 84,60\%, Puskesmas dapat memberikan pelayanan yang cepat dan tidak berbelit-belit $73,73 \%$, Puskesmas memberikan informasi pelayanan kesehatan terhadap masyarakat $86,10 \%$.
Menurut Tjiptono \& Chandra (2011), bahwa kehandalan (Reliability) yaitu kemampuan petugas dalam memberikan pelayanan sesuai yang dijanjikan secara akurat dan terpercaya yang berarti menuntut petugas bekerja secara cepat dan tepat dalam memberikan pelayanan kesehatan kepada pasien (12). Menurut Pohan (2002) pelayanan kesehatan itu harus efisien dan tepat waktu yakni antrian tidak panjang, waktu tunggu pasien tidak lama. Waktu pelayanan tepat waktu, petugas kesehatan dating dan pulang dengan tepat waktu (8).

Begitu juga dengan hasil penelitian dari Handayani (2016) di Puskesmas Batu Retno, dimana hasil perhitungan tingkat kepuasan pada aspek kehandalan pelayanan kesehatan sebesar 72,09\% yang menunjukkan pasien puas. Begitu juga hasil penelitian Kuncoro dan Istiono (2017) di Puskesmas Kretek Bantul Yogyakarta responden menyatakan puas sebesar $62 \%$ terhadap kehandalan pelayanan yang diberikan dengan cepat (13).

Puskesmas Kebon Handil dapat memenuhi pelayanan yang dijanjikan kepada masyarakat serta perawat membantu dokter dengan baik merupakan kenyataan yang harus dipenuhi dengan sering melakukan brifing pada saat sebelum dan sesudah pelayanan agar pelayanan yang diharapkan sesuai dengan kenyataan (14).

\section{Dimensi Daya Tanggap (Responsiveness)}

Berdasarkan hasil penelitian, pencapaian dimensi daya tanggap di Puskesmas Kebon Handil Tahun 2020 $84,38 \%$. Ada empat atribut dimensi daya tanggap yaitu, Dokter bersedia mendengarkan keluhan dari pasien 84,84 $\%$, Petugas puskesmas memberikan 
informasi yang dibutuhkan dengan baik $85,19 \%$, Petugas puskesmas memberi tahu bila ada keterlambatan pemeriksaan pasien $84,07 \%$, Petugas Apotek memberitahu lamanya proses pemberian obat $83,42 \%$.

Menurut Tjiptono (2014), bahwa daya tanggap adalah keinginan petugas membantu pelanggan dan memberikan pelayanan dengan tanggap (12). Menurut Pohan (2002) tentang informasi,indikator kepuasannya adalah prosedur pelayanan harus jelas, ada prosedur penyuluhan kesehatan, petunjuk arah dan alur pelayanan ada, nama setiap ruangan harus lengkap, informasi biaya layanan harus ada, informasi buka tutup harus ada dan jelas (8).

Begitu juga dengan hasil penelitian dari Handayani (2016) di Puskesmas Batu Retno, dimana hasil perhitungan tingkat kepuasan pada aspek ketanggapan sebesar $72,88 \%$ yang menunjukkan pasien merasa puas (15). Begitu juga hasil penelitian Kuncoro dan Istiono (2017) di Puskesmas Kretek Bantul Yogyakarta responden menyatakan puas sebesar $63 \%$ terhadap ketanggapan dan kemampuan petugas dalam pelayanan (13).

Puskesmas Kebon Handil agar selalu berkomunikasi dengan pasien dalam memberikan pelayanan agar pasien mengetahui lamanya proses mengambil obat di apotek dan pasien dapat mengetahui apabila ada keterlambatan pelayanan. Komunikasi dapat dilakukan pada saat pasien menyerahkan resep serta alur pelayanan diletakkan pada tempat yang mudah dilihat dan dibaca oleh seluruh pengunjung yang datang ke Puskesmas Kebon Handil.

\section{Dimensi Jaminan / Assurance}

Berdasarkan hasil penelitian, pencapaian dimensi Jaminan terhadap tingkat pelayanan di puskesmas kebon handil tahun 2020 sebesar 84,63\%. Ada lima nilai atribut pada penelitian ini yaitu, Petugas puskesmas selalu sabar menghadapi keluh kesah pasien 84,24\%, Dokter selalu ramah terhadap setiap pasien yang datang ke ruangannya 83,54\%, Semua petugas puskesmas selalu menampilkan senyum terhadap pasien yang datang 85,04\%, Dokter dengan sabar memberi penjelasan mengenai penyakit yang diderita pasien 84,94\%, Dokter memberikan alasan atau timbulnya penyakit yang diderita pasien $85,43 \%$.

Menurut Tjiptono bahwa Jaminan / Assurance adalah mencakup pengetahuan, kesopanan dan sifat dapat dipercaya yang dimiliki para petugas bebas dari bahaya resiko atau keragu-raguan (12). Begitu juga dengan hasil penelitian dari Sri Handayani (2016) di Puskesmas Batu Retno,dimana atribut Assurance sebesar 72,22\% (15). Begitu juga hasil penelitian Kuncoro dan Istiono (2017) di Puskesmas Kretek Bantul Yogyakarta responden menyatakan puas sebesar 54\% terhadap jaminan dalam pelayanan yang diberikan oleh petugas (13).

Puskesmas harus memberikan jaminan kepada pasien bahawa dokter dan petugas kesehatan akan selalu ramah terhadap semua pasien yang datang ke ruangannya sesuai dengan tata nilai (Ramah) dan motto (Hati Iklas Senyum, Sapa dan Sopan) di puskesmas dalam melakukan pelayann, sehingga pasien akan merasa sembuh walaupun belum dilakukan pengobatan.

\section{Dimensi Empati / Emphaty}

Berdasarkan hasil penelitian, pencapaian dimensi empati di puskesmas kebon handil tahun 2020 sebesar 88,93\%. Ada tujuh atribut dari dimensi empati yaitu, Dokter selalu ingat terhadap permasalahan / keluhan pasien sebelumnya 
sebesar 86,72 \%, Dokter selalu menanyakan kabar dan keadaan pasien $86,30 \%$, Dokter selalu mendengarkan dengan seksama semua keluhan pasien $85,71 \%$, Dokter dapat mengenal setiap pasien yang dating berobat $87,53 \%$, Petugas pendaftaran puskesmas selalu menanyakan kabar dari setiap pasien yang dating 88,36\%, Petugas puskesmas dapat mengenal pasien dengan baik $88,50 \%$, Kesediaan petugas untuk minta maaf bila terjadi kesalahan 99,23\%.

Menurut Tjiptono menyatakan bahwa empati adalah kemudahan dalam melakukan hubungan komunikasi yang baik, perhatian dan memahami kebutuhan pelanggan, dengan mengenal pasien dengan baik, memghadapi pelanggan dengan cara yang penuh perhatian, mendengarkan keluhan dengan sabar dan baik (12). Begitu juga dengan hasil penelitian dari Handayani (2016) di Puskesmas Batu Retno, dimana atribut emphaty sebesar 72,89\% (15). Begitu juga hasil penelitian Kuncoro dan Istiono (2017) di Puskesmas Kretek Bantul Yogyakarta responden menyatakan puas sebesar $67 \%$ penilaian pasien terhadap petugas telah bersikap ramah dan sopan santun serta memberikan salam kepada pasien yang mendapatkan pelayanan (13).

Puskesmas pada atribut empati ini telah melakukan dengan baik sehingga pasien yang mendapatkan pelayanan di puskesmas kebon handil merasa puas dengan pelayanan yang diberikan hal ini dapat terlihat dari hasil penelitian bahwa harapan dan kenyataan sudah sesuai dengan keinginan pasien dan pada atribut ini puskesmas kebon handil dapat mempertahankan nya.

\section{Dimensi Tampilan Fisik / Tangibles}

Berdasarkan hasil penelitian, pencapaian dimensi bukti fisik di puskesmas kebon handil tahun 2020 sebesar 83,93\%. Ada 5 Atribut dari dimensi bukti fisik ini yaitu Puskesmas telah memiliki gedung yang bersih dan terawatt serta petugas yang rapi $85,15 \%$, Puskesmas telah memiliki peralatan kesehatan yang memadai $84,11 \%$, Puskesmas telah memiliki ruangan tunggu yang memadai untuk menunjang pasien yang dating 84,24, Puskesmas telah memiliki apotek dengan jumlah obat yang lengkap $80,87 \%$, Ruangan pemeriksaan pasien memadai dan terjaga privasinya.

Bukti fisik / tangebels yaitu tampaialan sarana dan prasarana fisik serta keadaan lingkungan sebagai bukti nyata dari pelayanan yang diberikan oleh pihak Puskesmas, keberadaan bukti fisik yang baik dipelayanan keseahatan sangat diperlukan untuk menarik minat pelanggan agar mempercayakan pelayanan kesehatannya (6). Indikator kepuasan pasien adalah ruang tunggu tidak pengap dan tidak berdesakan, kursi cukup,untuk jumlah pasien, privasi terjamin, toilet bersih, puskesmas bersih, tong sampah ada, kamar pemeriksaan tertutup ada skat gorden (16)(17). Begitu juga dengan hasil penelitian Handayani (2016) di Puskesmas Batu Retno, dimana atribut tangibel sebesar $72,76 \%$ (15). Begitu juga hasil penelitian Kuncoro dan Istiono (2017) di Puskesmas Kretek Bantul Yogyakarta responden menyatakan puas sebesar $59 \%$ pasien puas terhadap dimensi tangible (13).

Hal ini disebabkan puskesmas kebon handil dalam tahap renovasi sehingga kenyamanan pasien terganggu, ruang tunggu yang sedikit gelap dan banyak 
debu hasil dari pembongkaran gedung, untuk itu puskesmas diharapkan menambah penerangan di ruang tunggu dan selalu menjaga kebersihan.

\section{KESIMPULAN}

Berdasarkan penelitian yang telah dilakukan terhadap tingkat kepuasan pelayanan puskesmas kebon handil tahun 2020 maka dapat disimpukan sebagai berikut :

Tingkat kepuasan pasien dengan melihat kesesuaian sebesar $84,18 \%$ dari atribut harapan dan kenyataan terhadap 5 dimensi mutu.

Tingkat kepuasan pasien dengan melihat kesesuaian sebesar $86,28 \%$ dari atribut harapan dan kenyataan terhadap dimensi mutu kehandalan / Reliability.

Tingkat kepuasan pasien dengan melihat kesesuaian sebesar $84,38 \%$ dari atribut harapan dan kenyataan terhadap dimensi mutu daya tanggap / responsiveness

Tingkat kepuasan pasien dengan melihat kesesuaian sebesar $84,63 \%$ dari atribut harapan dan kenyataan terhadap dimensi mutu jaminan / assurance

Tingkat kepuasan pasien dengan melihat kesesuaian sebesar $88,93 \%$ dari atribut harapan dan kenyataan terhadap dimensi mutu empati / emphaty.

Tingkat kepuasan pasien dengan melihat kesesuaian sebesar 78,33\% dari atribut harapan dan kenyataan terhadap dimensi mutu bukti fisik / tangible.

Berdasarkan analisa diagram kartesius aspek dimensi mutu yang menjadi prioritas utama untuk diperbaiki yaitu dimensi tangible dimana puskesmas harus memiliki obat yang lengkap, puskesmas juga harus melengkapi peralatan keseahatan serta puskesmas menyiapkan ruang tunggu yang dapat menunjang pasien yang datang.

\section{SARAN}

Disarankan kepada Puskesmas Kebon Handil untuk melakukan bebrapa hal sehingga kenyataan dan harapan yang diinginkan dapat terlaksana antara lain adalah:

1. Agar puskesmas memperhatikan persediaan obat dan alat keseahatan yang sesuai dengan standar yang telah ditetapkan.

2. Agar puskesmas memberikan kenyamanan ruang pemeriksaan (ruang yang tertutup) agar privasi pasien dapat terjaga.

3. Agar puskesmas menyediakan ruang tunggu yang memadai dan nyaman sehingga memberikan kenyamanan pada saat pasien antri menunggu pelayanan.

Bagi Peneliti selanjutnya disarankan pada peneliti lain agar dapat melakukan penelitian lebih khusus lagi pada atribut dimensi yang berbeda untuk melihat kenyataan dari pelayanan yang diinginkan oleh masyarakat untuk meningkatkan kepuasan pelayan keseahatan, bagi STIKES HI agar melengkapi bahan bacaan khusus tentang tingkat kepuasan pelayanan dan diharapkan hasil penelitian ini dapat dijadikan salah satu bahan tambahan referensi ilmu yang ada di perpustakaan

\section{DAFTAR PUSTAKA}

1. Anwar Hidayat, 2017, Metode Penelitian Deskritif

2 Azrul Azwar. 2010. Menjaga Mutu Pelayanan

3. Aziz Slamet Wiyono, 2006, Studi Tentang Kualitas Pelayanan dan Kepuasan Konsumen di Rumah Sakit Islam Manisrenggo Klaten

4. Bagian Organisasi Setda Kota Jambi 2018. Laporan Indeks Kepuasan Masyarakat 2018 
5. Bagian Organisasi Setda Kota Jambi 2018. Laporan Indeks Kepuasan Masyarakat 2019

6. Departmen Kesehatan RI . 2007. Sistem Kesehatan. Jakarta.

7. Imbolo.S.Pohan,2006. Jaminan Mutu Layanan Kesehatan

8. J.Supranto, 2011. Pengukuran Tingkat Kepuasan Pelanggan

10. Kepmenkes RI No. 128 /Menkes/ SK/II/2004, Tentang Puskesmas

11. Notoatmodjo, Soekidjo. 2010, Promosi Kesehatan Teori dan Aplikasi, Jakarta: Rineka Cipta

12. Notoatmodjo, Soekidjo. 2010, Promosi Kesehatan Teori dan Aplikasi, Jakarta: Rineka Cipta

13. Permenkes RI Tahun No 75 Tahun 2015. Tentang Puskesmas

14. Permenpan Nomor 14 Tahun 2017. Pedoman Penyusunan Survey Kepuasan Masyarakat Unit Penyelengara Pelayanan Publik.
15. Philip Kotler 2008, Manajemen Pemasaran

16. Profil Puskesmas Kebon Handil Kota Jambi Tahun 2019

17. Tjiptono, Fandi \& Chandra, Greorius, (2011). Service Quality \& Satisfaction. (Edisi 3). Yogyakarta : Andi Offset

18. Undang-Undang Nomor 25 Tahun 2009 Tentang Pelayanan Publik

19. Undang-Undang No 32 Tahun 2004, Tentang Pemerintah Daerah

20. Wahyu Kuncuro,Wahyudi Istiono, 2017, Kepuasan Pasien terhadap Kualitas Pelayanan di Tempat Pendaftaran Pasien Rawat Jalan Puskesmas Kretek Bantul Yogyakarta.

21. Wijono 1999, Manajemen Mutu Pelayanan Kesehatan. 